\title{
Influence of host plants on specialist / generalist aphids and on the development of Adalia bipunctata (Coleoptera: Coccinellidae)
}

\author{
FrÉdÉRIC FRANCIS, ERIC HAUBRUGE and ChARLES GASPAR \\ Unit of General and Applied Zoology, Gembloux Agricultural University, Passage des Déportés 2, B-5030 Gembloux, Belgium; \\ e-mail: francis.f@fsagx.ac.be
}

Key words. Brassicaceae, aphid, ladybird, tritrophic interaction, biological control

\begin{abstract}
The aim of this work was to determine the impact of allelochemicals (glucosinolates/isothiocyanates) from Brassicaceae (Brassica napus and Sinapis alba) at two trophic levels in relation to biological control efficacy. The impact of these plants on aphid Myzus persicae (Sulzer) and Brevicoryne brassicae (L.) and ladybird Adalia bipunctata (L.) biology can be assessed by observation of several developmental parameters: mortality, development duration and adult weight. Sub-lethal toxicity can also be measured through the reproductive parameters of fecundity and/or egg viability. While both specialist and generalist aphids were positively influenced by Brassicaceae species, mixed effects are recorded in ladybird performances following the aphid species/host plant combinations. Significant differences appeared according to aphid host plant and aphid species. This work enhanced the influence of Brassicaceae plants either as cultivated species (B. napus) or as set-aside ( $S$. alba) on both pests and beneficial insects. The allelochemical presence in plants must be taken into account in programs of integrated pest management due to their direct influence on biological control agents.
\end{abstract}

\section{INTRODUCTION}

Considerable research on plant - insect interactions has been undertaken to improve crop production. Many physical (Mangold, 1978) or chemical cues from plants or insects are known to be essential in the effective location of the host/prey habitat by entomophagous insects. The impact of semiochemicals on both herbivores and entomophagous insects are often neglected. Herbivore nutrition also influences the emitted odours and the searching behaviour of their biological control agents (Sauls et al., 1979).

As in many other botanical families, Brassicaceae species include secondary compounds which display physiological properties (phago- and ovipostimulant) on insects feeding on them (Lerin, 1980; Lamb, 1989). Glucosinolates, thioglucosides compounds, are present in all parts of Brassicaceae species. These substances were detected in 11 dicotyledone families (Fenwick et al., 1983). The myrosinase enzyme (thioglucoside glucohydrolase) occurs together with glucosinolates although they are held separately and any process which reduces the cellular integrity of the plant tissues results in the enzyme induced breakdown of glucosinolates (Heaney \& Fenwick, 1995). When tissues are damaged, the toxic hydrolysis products of glucosinolates are released. These compounds include thiocyanates, nitriles and isothiocyanates and are thought to constitute part of the plant's defence (Porter et al., 1991).

The importance of chemical ecology, particularly between aphids and their hymenopteran parasitoids, was addressed by Pickett et al. (1992). Aphids are major pests in temperate regions causing direct damage by sap taking but also by virus transmission. Aphidophagous Coccinellidae such as Adalia bipunctata are important predators and are polyphagous to a broad range of aphid species including Myzus persicae (Sulzer) (Hodek \& Honěk, 1996). Nevertheless, only a limited number of aphid species, excluding Brevicoryne brassicae (L.), are suitable as food for A. bipunctata (Blackman, 1967 ; Majerus, 1994). Host plant influence on predator biology has been rarely investigated. The aim of this work was to determine the impact of allelochemicals from plants in relation to biological control efficacy. Brassicaceae plant species used in this work were chosen for their allelochemical profiles: high amounts of glucosinolates are present in Sinapis alba L. compared to their low content in Brassica napus L. (around six fold less). Vicia faba L. which does not include glucosinolate was used as control. While Brassicaceae specialists, such as $B$. brassicae, are stimulated to feed and oviposit by these substances, generalist herbivores are usually deterred. Due to its high polyphagy, $M$. persicae is found on Brassicaceae plants and tolerates the glucosinolate compounds (Nault \& Stayer, 1972). The plant impact on entomophagous insects through the prey can be assessed by several biological parameters. Direct toxicity can be assessed by the mortality, weight and developmental duration of $A$. bipunctata. Sub-lethal toxicity can also be measured through the reproductive parameters of fecundity and/or egg viability.

\section{MATERIALS AND METHODS}

\section{Plants and insect rearing}

White mustard (S. alba), oilseed rape (B. napus, Alaska variety) and broad bean $(V . f a b a)$ were raised in $10 \mathrm{~cm}$ diameter plastic pots in a controlled environment room at $20 \pm 2^{\circ} \mathrm{C}$ temperature and $16 \mathrm{~h}$ daylight photoperiod. Brassicaceae species were first sown in an incubator at $16^{\circ} \mathrm{C}$ in a plastic tray containing ordinary compost and placed in plastic pots with the 
same substrate when the plants had two true leaves. Broad beans were sown directly in a mixture of perlite and vermiculite.

$A$. bipunctata and $M$. persicae had been reared in the laboratory for several years whereas $B$. brassicae was collected from a white mustard field in September 1998. Aphid species were mass reared on rape and mustard which were inoculated when they had 5-6 true leaves. Broad beans were used when they reached a 3-4 cm height. Aphids stayed at least two weeks on their host plants before utilisation as food for the ladybirds.

\section{Experimental observations}

Several measures of performance were calculated for the aphid species on each host plant and for the ladybirds fed with each combination aphid/host plant.

\section{Aphid reproductive rate}

Ten host plants of each species were randomly chosen in the plant population and were inoculated with ten apterous adults. Each plant was individually placed in a net cage and was observed every $24 \mathrm{~h}$ for 7 days. The change in aphid numbers was recorded for ten replicates.

\section{Ladybird development stages}

For each experiment (combination aphid species/host plant), thirty newly hatched larvae of $A$. bipunctata were isolated individually in a $5 \mathrm{~cm}$ diameter Petri dish to avoid cannibalism. The larvae were collected from different egg clusters from the ladybird stock culture fed with Acyrthosiphon pisum (Harris). Each experiment was repeated twice leading to 60 replicates per beetle diet (each aphid/host plant combination). Aphids removed from their host plants, which were cultivated in separate climate rooms, were offered to the larvae ad lib. From hatching, larvae were kept at $20 \pm 2^{\circ} \mathrm{C}$ temperature with $16 \mathrm{~h}$ light period and observed every day to determine the survival and the ecdysis of larvae until pupal stage. Time needed for each change of stage was recorded. Ladybirds were weighed at adult emergence using an Ohaus Explorer balance.

\section{Statistical analysis}

For aphid reproduction, linear regressions were calculated for each aphid host plant followed by an equality test of the slopes (regression coefficients : $\beta_{\mathrm{yx}}$ ). Ladybird parameters were examined by analysis of variance (ANOVA) followed by means comparison with the least significant difference method when needed. MINITAB (vs 11.2) was used for the statistical analysis.

\section{RESULTS}

\section{Aphid reproductive rates}

After having compared the slopes (29.0 and 53.6 for $S$. $a l b a$ and $B$. napus respectively) from the linear regression equations, significant difference was observed depending on the host plant of $M$. persicae $(\mathrm{t}=7.75$ and $\mathrm{P}<0.001)$ (Fig. 1). For B. brassicae, the slope corresponding to $B$. napus is also significantly higher than the one involving $S$. alba (23.6 and 9.20 respectively; $t=13.63$ and $\mathrm{P}<0.001$ ) (Table 1).

\section{Ladybird parameters}

When $M$. persicae or B. brassicae reared on B. napus were used to feed the ladybirds, the larval development duration of $A$. bipunctata was significantly higher for $B$. brassicae $(\mathrm{F}=199.49$ and $\mathrm{P}<0.001)$ and the same result was observed for pupal duration $(F=19.64$ and $\mathrm{P}<0.001)$.
TABLE 1. Linear regression equations and the respective determination coefficients corresponding to Sinapis alba and Brassica napus when used as host plant of Myzus persicae or Brevicoryne brassicae.

\begin{tabular}{clc}
\hline $\begin{array}{c}\text { Aphid species/host } \\
\text { plant }\end{array}$ & $\begin{array}{c}\text { Linear regression } \\
\text { equation }\end{array}$ & $\begin{array}{c}\text { Determination } \\
\text { coefficients }\end{array}$ \\
\hline Myzus/B. napus & $\mathrm{y}=53.6 \mathrm{x}-5.59$ & $\mathrm{R}^{2}=0.992$ \\
Myzus/S. alba & $\mathrm{y}=29.0 \mathrm{x}-12.09$ & $\mathrm{R}^{2}=0.978$ \\
Brevicoryne/B. napus & $\mathrm{y}=23.6 \mathrm{x}-6.00$ & $\mathrm{R}^{2}=0.982$ \\
Brevicoryne/S. alba & $\mathrm{y}=9.2 \mathrm{x}+4.34$ & $\mathrm{R}^{2}=0.971$ \\
\hline
\end{tabular}

The effect of three host plants of aphid species (Fig. 2) when used as food for $A$. bipunctata was studied. It was not possible to compare statistically the total development duration of ladybirds fed with $B$. brassicae reared either on $B$. napus or $S$. alba. No larvae fed with the latter combination were able to complete their development cycle and reach the adult stage. At adult emergence, weights of $A$. bipunctata fed either with $M$. persicae or B. brassicae reared on B. napus were compared (Fig. 3). A significant difference was observed for the two aphid species $(\mathrm{F}=$ 302.84 and $\mathrm{P}<0.001$ ). When $S$. alba was used as host plant, the average weight of the ladybird fourth instar larvae was $3.94 \pm 0.34 \mathrm{mg}$. The loss of weight due to pupation is around 20\% (Francis, unpubl.). At emergence, adults would have been lighter than the ones from $M$. persicae/host plant combination.

The effect of the aphid host plant on the duration of each larval stage of ladybird fed with $M$. persicae or $B$. brassicae reared on one of the two host plants ( $B$. napus or $S$. alba), was assessed (Figs 4a, b). When $M$. persicae was used, significant differences in development durations were observed for the 3rd and 4th larval instars and the pupal stage $(\mathrm{F}=35.59$ and $\mathrm{P}<0.001 ; \mathrm{F}=53.82$ and $\mathrm{P}<0.001 ; \mathrm{F}=77.51$ and $\mathrm{P}<0.001$ respectively)

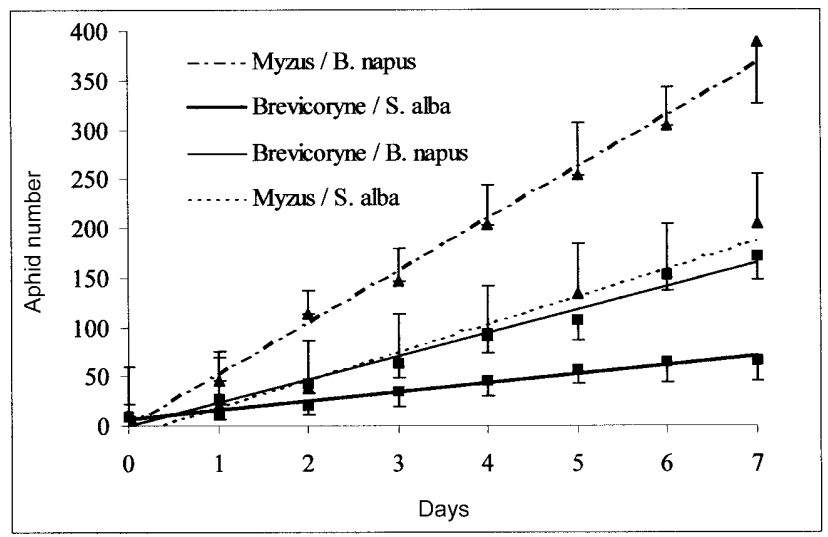

Fig. 1. Effect of the host plant on the reproduction of Myzus persicae and Brevicoryne brassicae. Each point is the mean of 10 replicates, bars represent standard deviations.

depending on the host plant. $M$. persicae host plant did not display significant differences for the 1 st and 2 nd larval instars $(\mathrm{F}=3.45$ and $\mathrm{P}=0.066 ; \mathrm{F}=0.64$ and $\mathrm{P}=$ 0.426 , respectively).

When ladybird larvae were fed with $B$. brassicae reared either on $B$. napus or $S$. alba, significant differences were 


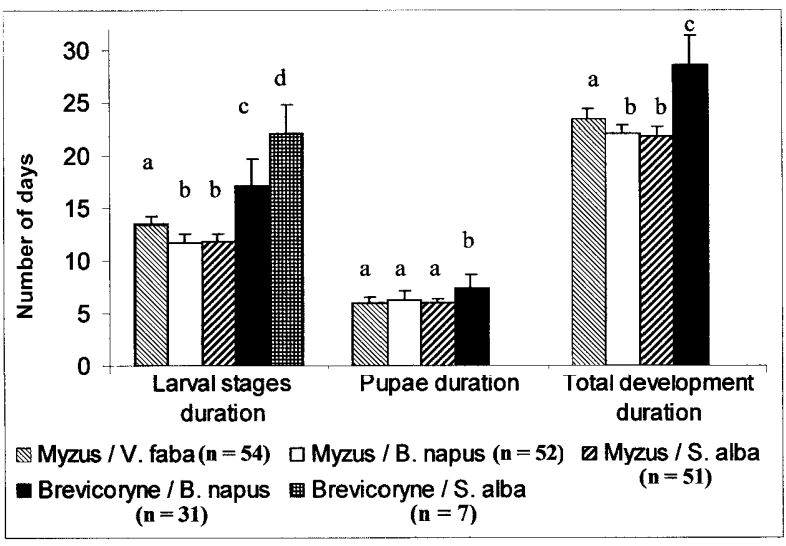

Fig. 2. Effect of the aphid - prey host plant (Sinapis alba, Brassica napus and Vicia faba) on larval, pupal and total (egg to adult) development periods of Adalia bipunctata fed with Myzus persicae or Brevicoryne brassicae. Individual numbers reaching the adult stage are represented by $\mathrm{n}$ values. Letters indicate significant differences at $\mathrm{P}=0.001$.

observed at each larval instar according to the host plant species. The statistical values were $\mathrm{F}=75.43$ and $\mathrm{P}<$ $0.001 ; \mathrm{F}=14.18$ and $\mathrm{P}=0.001 ; \mathrm{F}=43.75$ and $\mathrm{P}<0.001$ for the 1st, 2nd and 3rd larval instars, respectively. No comparison was made for the 4th larval instar and the pupal stage; no ladybirds fed with $B$. brassicae from $S$. alba reached the last larval instar.

\section{DISCUSSION}

Plant - insect interactions have existed for millions of years and have lead to a co-evolution of both protagonists. In tritrophic systems, the third level (here, the aphidophagous organisms) must be considered as a part of the plant defence system (Poppy,1997).

While the toxicity of glucosinolate metabolites from Brassicaceae plants is well known (Blau et al.,1978; Erickson \& Feeny, 1974), the influence of these substances on predators through aphid prey has still to be studied. The biological effect of Brassicaceae (including allelochemicals as glucosinolates/isothiocyanates) on both

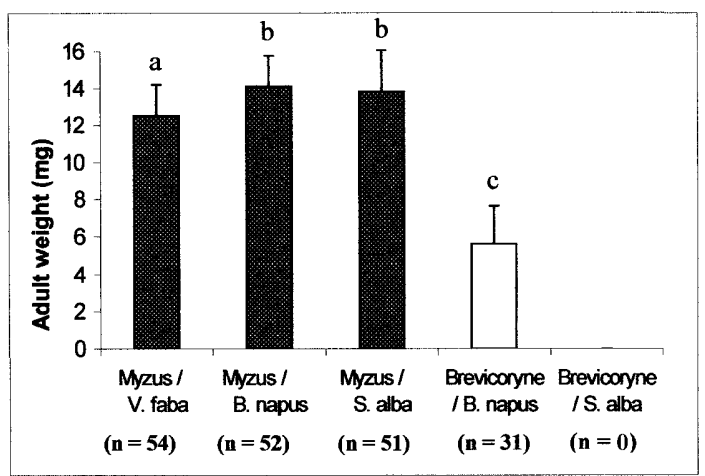

Fig. 3. Effect of the aphid-prey host plant (Sinapis alba, Brassica napus and Vicia faba) on adult weight of Adalia bipunctata fed with Myzus persicae or Brevicoryne brassicae. Individual numbers reaching the adult stage are represented by $\mathrm{n}$ values. Letters indicate significant differences at $\mathrm{P}=0.001$. specialist/generalist aphid species (changes of reproductive rates of $B$. brassicae and $M$. persicae) has been confirmed here and extended to aphidophagous predators. The variations of the ladybird development duration were directly correlated to the host plant of both herbivore species. The adult weight of $A$. bipunctata is influenced by the Brassicaceae plant which could cause changes in the ladybird reproduction. In the B. brassicae/S. alba combination, no ladybird reached the adult stage. When rape ( $B$. napus) was used as host plant of $B$. brassicae, no coccinellid egg was laid up to 21 days after adult emergence (Francis, unpubl.). This result is in accordance with previous studies. $B$. brassicae was generally avoided by $A$. bipunctata and is also slightly less suitable than other aphids for Coccinella septempunctata (Blackman, 1965, 1967) and Harmonia axyridis (Hukusima \& Kamei, 1970). The host plant of $M$. persicae also influences reproduction in $A$. bipunctata. Indeed, the ladybird fecundity is significantly different when the aphid prey was reared either on rape or white mustard (during a 21 day period, $8.38 \mathrm{eggs} /$ female/day and $3.79 \mathrm{eggs} /$ female/day respectively). Egg viability of $A$. bipunctata also depends on the aphid host plant $(65 \%, 57 \%$ and $48 \%$ for bean, rape or white mustard respectively) and seems to be linked to the glucosinolate level in plant (Francis et al., unpubl.).

Dixon (1985) suggested a close relationship between aphid nutrition and development. Cole (1997) concluded that the glucosinolate profiles of Brassicaceae plants had a significant impact on the development and performance of both B. brassicae and M. persicae. Moreover, the Brassica juncea, B. napus and B. campestris host suitability for the mustard aphid, Lipaphis erysimi, was not found to be related to the composition or concentrations of amino acids. The difference in aphid reproductive rates must be due to factors other than nutritional status of the phloem sap (Weibull \& Melin, 1990).

The control of crop pests based on the utilisation of chemical substances from plants such as semiochemicals, with non-toxic mode of action, should be combined with the use of biological agents. The oilseed rape agroecosystem represents a useful model to explore such an approach (Pickett et al., 1995). Assays including deterrent/anti-nutritional substances or trap plants (due to attractive/stimulant presence) have been undertaken to reduce herbivore infestations. A complementary strategy would be to determine the effect of these allelochemicals on entomophagous insects to obtain optimal control of the herbivores in integrated pest management. Entomophagous biological agents can be directly influenced by plants: the latter can affect the prey quality (nutritional value, toxicity) or the searching mechanism of their host/prey (Vet \& Dicke, 1992).

Besides biological observations, chemical analyses of aphids were performed (Francis et al., in press). Samples of each host plant/aphid species combination were analysed by liquid chromatography (HPLC). Significant amounts of glucosinolates were found in M. persicae fed on white mustard and rape. No degradation products of 

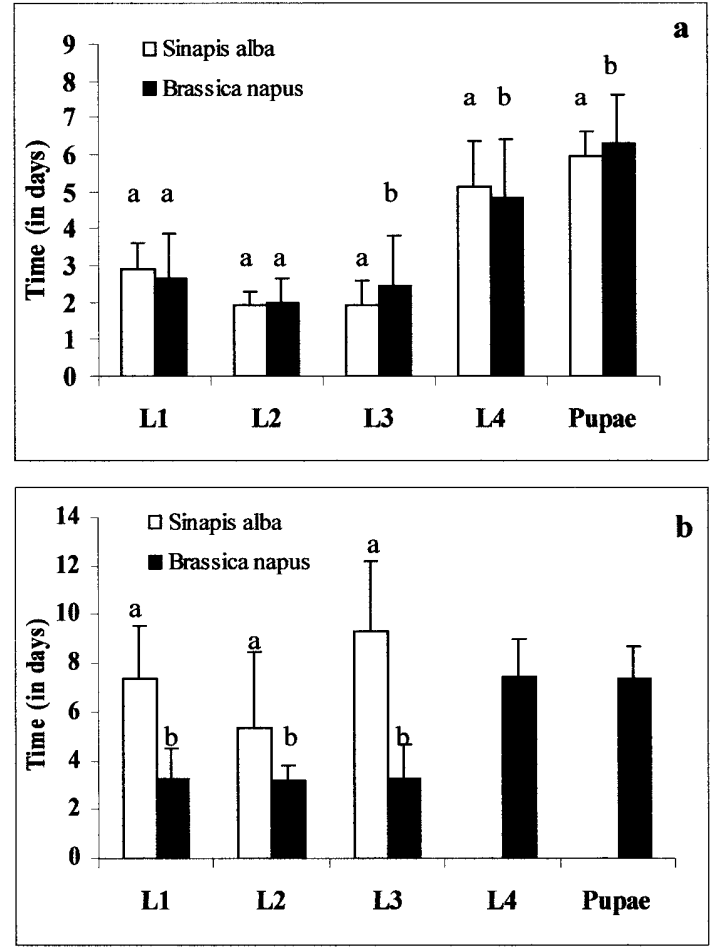

Fig. 4 a-b: Effect of the aphid - host plant (Sinapis alba, Brassica napus and Vicia faba) on the development period for larval and pupal stages of Adalia bipunctata fed with Myzus persicae - $\mathrm{a}$; and Brevicoryne brassicae - b; letters indicate significant differences at $\mathrm{P}=0.001$ for pairwise comparisons.

the glucosinolates were detected by gas chromatography analysis coupled to mass spectrophotometry (GC-MS) in $M$. persicae infesting either B. napus or $S$. alba. However, isothiocyanates (ITC) were identified in $B$. brassicae. The higher toxicity of the latter species can be explained by the presence of these ITC compounds. Indeed, Francis et al. (1999) demonstrated that $A$. bipunctata exposed to allyl ITC and methyl ITC died from a 0.15 ppm concentration of toxic compounds. Moreover, myrosinase enzyme, which catalyses the glucosinolate degradation, was detected in B. brassicae but not in M. persicae (Francis, 1999).

A hypothesis has already been put forward concerning the effect of allelochemicals from plants on aphidophagous predators. The harmfulness of some prey seems to result from the presence of allelochemicals showing toxic properties. Larvae of $C$. septempunctata could not complete their development and died within 25 days when fed with Aphis sambuci (Hodek, 1956). Blackman (1965, 1967) observed a less detrimental effect of this aphid species. Indeed, half of the individuals reached the adult stage even if they were twice lighter in weight than control ladybirds. A passage of the glycoside sambunigrin from the Sambucus nigra plant into the aphid was assumed (Hodek, 1956). This glycoside may be split enzymatically into hydrocyanic acid in the ladybird body. Several other aphid species seem to be poisonous to many coccinellids including $A$. bipunctata and rejected by ladybirds due to the presence of allelochemical: for example,
Macrosiphum aconitum feeding on Aconitum (containing aconitin; Hawkes, 1920), Aphis nerii infesting oleanders (containing oleadrin and neriin, cardiac glycosides cardenolides; Malcolm, 1990), Macrosiphum albifrons and Aphis jacobaeae feeding on Lupinus mutabilis (with quinolizidine alkaloids) and Senecio sp. (containing pyrolizidine alkaloids) respectively (Hodek \& Honěk, 1996).

Acceptance of aphid species does not inevitably imply food suitability. Indeed, Coccinellidae sometimes consume prey even if it is not an adequate food. Development and reproduction parameters are then negatively influenced (Hodek \& Honěk, 1996). The different aphid/host plant combinations used in this work to feed $A$. bipunctata can be classified as followed:

$M$. persicae on either $V$. faba (without glucosinolate) or $B$. napus (including low rate of glucosinolates) as essential foods (ensuring completion of development and oviposition);

$M$. persicae on $S$. alba (with high amount of glucosinolates) as accepted food (enabling development without high mortality but displaying negative effects on oviposition; Francis et al., unpubl.);

$B$. brassicae on B. napus as alternative food (implying higher mortality, longer development duration and restricted oviposition);

B. brassicae on $S$. alba as toxic food (implying total mortality, before the adult stage is reached).

In conclusion, the determination of the aphid prey natural enemy relationship should be integrated in tritrophic models including host plant to assess the impact of each level and to set effective ways of biological control. The correct choice of the beneficial insect seems to be essential to cope with a specific crop pest. For aphid species, the cultivated plant varieties also play a role in the herbivore - predator relationsh ip and the allelochemicals present can significantly influence the efficacy of entomophagous insects (van Emden, 1995).

\section{REFERENCES}

Blackman R.L. 1965: Studies on specificity in Coccinellidae. Ann. Appl. Biol. 56: 336-338.

Blackman R.L. 1967: The effects of different aphid foods on Adalia bipunctata L. and Coccinella 7-punctata L. Ann. Appl. Biol. 59: 207-219.

Blau P.A., Feeny P., Contardo L. \& Robson D.S. 1978: Allylglucosinolate and herbivorous caterpillars: a contrast in toxicity and tolerance. Science (Washington) 200: 1296-1298.

Cole R.A. 1997: The relative importance of glucosinolates and amino acids to the development of two aphid pests Brevicoryne brassicae and Myzus persicae on wild and cultivated brassica species. Entomol. Exp. Appl. 85: 121-133.

Dixon A.F.G. 1985: Aphid Ecology, 2nd edition. Chapman \& Hall, London, $300 \mathrm{pp}$.

ERICKSON J.M. \& FEENY P. 1974: Sinigrin: a chemical barrier to the black swallowtail butterfly, Papilio polyxenes. Ecology 55: 103-111.

Fenwick G.R., Heaney R.K. \& Mullin W.J. 1983: Glucosinolates and their breakdown products in food and food plants. CRC, Critical Rev. Food Sci. Nutrition 18: 123-201. 
Francis F. 1999: Conséquences évolutives des relations entre le puceron et son prédateur en présence de substances allélochimiques chez les Brassicaceae. 5ème Conférence Internationale sur les Ravageurs en Agriculture, Annales ANPP, Tome II, 503-510.

Francis F., Haubruge E. \& Gaspar C. 1999: Effects of isothiocyanates on the glutathione S-transferases activity from Adalia bipunctata L. (Coleoptera: Coccinellidae). Med. Fac. Landbouw. Univ. Gent 64(3a): 297-303.

Francis F., Lognay G., Wathelet J.P. \& Haubruge E. (in press) Effects of allelochemicals from first (Brassicaceae) and second (Myzus persicae \& Brevicoryne brassicae) trophic levels on Adalia bipunctata. J. Chem. Ecol.

HAWKES O.A.M. 1920: Observations on the life-history, biology and genetics of the ladybird beetle Adalia bipunctata. Quoted in Hodek I \& Honěk A. 1996.

HeAney R.K. \& Fenwick G.R. 1995: Natural toxins and protective factors in Brassica species, including rapeseed. Natural Toxins 3: 233-237.

HoDEK I. 1956: The influence of Aphis sambuci L. as prey of the ladybird beetle Coccinella 7-punctata L. Věst. Čsl. Spol. Zool. 20: $62-74$.

Hoder I. \& HonĚK A. 1996: Ecology of Coccinellidae. Kluwer Academic Publisher, The Netherlands, $464 \mathrm{pp}$.

HuKusma S. \& KameI M. 1970: Effects of various species of aphids as food on development, fecundity and longevity of Harmonia axyridis (Coleoptera, Coccinellidae). Quoted in Hodek I. \& Honěk A. 1996.

LaMB R.J. 1989: Entomology of oilseed Brassica crops. Annu. Rev. Entomol. 34: 211-229.

LERIN J. 1980: Influence des substances allélochimiques des crucifères sur les insectes. Acta Oecologica 1:3: 215-235.

Majerus M.E.N. 1994: Ladybirds. The New Naturalist, London, $367 \mathrm{pp}$.

MALCOLM S.B. 1990: Chemical defence in chewing and sucking insect herbivores: plant-derived cardenolides in the monarch butterfly and oleander aphid. Chemoecol. 1: 12-21.
MANGOLD J.R. 1978: Attraction of Euphasiopteryx ochracea, Corethrella sp. and gryllids to broadcast songs of the southern male cricket. Florida Entomol. 61: 57-61.

Nault L.R. \& Stayer. W.E. 1972: Effects of sinigrin on host selection by aphids. Entomol. Exp. Appl. 15: 423-437.

Pickett J.A., L.J. Wadhams \& Woodcock C.M. 1992: The chemical ecology of aphids. Annu. Rev. Entomol. 37: 67-90.

Pickett J.A., Butt T.M., Doughty K.J., Wallsgrove R.M. \& Williams I.H. 1995: Minimising pesticide input in oilseed rape by exploiting natural regulatory processes. 9th International Rapeseed Congress, Cambridge, 4-7th July 1995, vol $2,565-571$.

Poppy G.M. 1997: Tritrophic interactions: improving ecological understanding and biological control? Endeavour 21(2): $61-65$.

Porter J.R., Morton A.M., Kiddle G., Doughty K.J. \& WallsGROVE R.M. 1991: Variation in the glucosinolates content of oilseed rape (Brassica napus L.) leaves. Effect of leaf age and position. Ann. Appl. Biol. 118: 461-467.

Sauls C.E., Nordlund D.A. \& Lewis W.J. 1979: Kairomones and their use for management of entomophagous insects. VIII. Effect of diet on the kairomonal activity of frass from Heliothis zea (Boddie) larvae for Microplitis croceipes (Cresson). J. Chem. Ecology 5: 363-369.

VAN EMDEN H.F. 1995: Host plant-Aphidophaga interactions. Agr. Ecosys. Envir. 52: 3-11

Vet L.E.M. \& Dicke M. 1992: Ecology of infochemical use by natural enemies in a tritrophic context. Annu. Rev. Entomol. 37: 141-172.

Weibull J. \& Melin G. 1990: Free amino acid content of phloem sap from Brassica plants in relation to performance of Lipaphis erysimi (Hemiptera: Aphididae). Ann. Appl. Biol. 116: $417-423$.

Received January 18, 2000; accepted June 6, 2000 